\title{
Transmedia, sofistas y el jogo bonito. Caso de estudio: Santander Fútbol Pasión
}

\author{
Álvaro Doladé \\ Cofundador de Flying October
}

\section{Referencia de este artículo}

Doladé, Álvaro (2017). Transmedia, sofistas y el jogo bonito. Caso de estudio: Santander Fútbol Pasión. En: adComunica. Revista Científica de Estrategias, Tendencias e Innovación en Comunicación, $\mathrm{n}^{0} 14$. Castellón: Asociación para el Desarrollo de la Comunicación adComunica y Universitat Jaume I, 251-253. DOI: http://dx.doi.org/10.6035/2174-0992.2017.14.13

En la facultad disfruté mucho de las sesiones de Lluís Pastor, un virtuoso de la docencia. Varias veces nos introdujo a Protágoras y cuando lo hacía impostaba la voz definiéndole como "el Ronaldinho de la retórica". Los dos fueron y son referentes en el arte de deleitar y persuadir a las masas. El brasileño por su destreza con el balón; el sofista por su elocuencia al emplear la palabra. Es a éste último a quien se le atribuye el famoso principio filosófico que reza "El hombre es la medida de todas las cosas".

¿Pero qué tiene que ver Protágoras con el transmedia? Tras años de experiencia en campañas multiformato, o lo que viene a conocerse como branded content, me permitiré una licencia: reformular el enunciado del pensador griego para adaptarlo a nuestro contexto donde "El usuario es la medida de todas las campañas".

Es el usuario, es una usuaria, pongamos a María, quien da sentido a la narrativa. Es a María a quien tenemos que emocionar, provocar y llamar a la acción. Es a ella a quien debemos abrir espacios de interacción para generar el tan ansiado 
engagement. Es pensando en ella cuando tenemos que crear "contenidos comestibles” y bien hilados. Será entonces cuando los KPI (indicadores clave de rendimiento) se lograrán. Si no, existe el riesgo de inconexión y que elija otra opción de entretenimiento: una serie, un videojuego, Whatsapp o jugar con su gato.

Dicho de otra manera: la marca debe ceder el protagonismo a María para convertirse en un facilitador de experiencias y emociones, a través de las cuales refleje sus valores de marca. La experiencia de usuario es la clave. Parece sencillo decirlo, pero aún hoy en 2017 hay marcas que se resisten a permitir que los usuarios sean sus cocreadores. Como decía Roy Batty en Blade Runner, "he visto cosas que vosotros no creeríais".

Para respaldar lo que digo, compartiré un caso de éxito en el que tuve el privilegio de participar, junto a un fantástico equipo multidisciplinar: Santander Fútbol Pasión. Una competición transmedia creada por Ogilvy \& Mather Madrid. En 2013 y 2014 ganó dos récords Guinness al concurso deportivo con mayor participación de la historia. Un dato: en la edición de 2013, entre todos los jugadores sumaron 325.000 horas de participación. Es decir, más de 37 años de juego...

La oportunidad surgió desde Santander, quien buscaba posicionarse como "el banco del fútbol en Latinoamérica”. La propuesta de agencia fue un concurso de preguntas y respuestas multipantalla y multiplataforma: con fases online, una fase telefónica y una final emitida por televisión.

La idea se consolidó a partir de un insight potente: 'Todos nos creemos los mayores expertos en fútbol”. Después, una llamada a la acción, que era un torpedo a la línea de fletación de su orgullo: 'Buscamos a la persona que más sabe de fútbol en Latinoamérica'. Y como colofón, un premio económico (30.000\$ dólares americanos en varias ediciones) para un único campeón, en una gran final emitida en televisión para todo el continente. En resumen: una competición de dimensiones globales, construida desde las emociones y sentimientos de los hinchas y forofos.

Para lograr el mayor número de registros posibles, entre la agencia y el cliente elaboramos un mapa de touchpoints con el usuario, integrado en una estrategia de medios propios, medios pagados y medios ganados. Por compartir algunos ejemplos: emails comunicando la apertura de cada fase, comodines dinamizadores del juego, banners adaptados a los productos de cada país, logros y rankings compartibles en redes sociales o vídeos motivadores de Pelé y Neymar en los diferentes canales.

Además, año tras año fuimos perfeccionando el juego, siempre desde el feedback que nos proporcionaban los propios usuarios, datos y las métricas de ediciones anteriores.

¿El resultado? En la primera edición de Santander Fútbol Pasión, en 2012, participaron 240.000 personas y ganó José Alberto Ramos de México. En la segunda 1,15 millones y Luzinei Neves (Brasil) se proclamó campeón. En el 
tercer año, 1,7 millones de participantes y un uruguayo, Pablo Gómez, subió a lo más alto del podio. Finalmente, en 2016 1,4 millones de jugadores y esta vez el vencedor resultó ser el argentino Pablo Dragún. En total casi 4,5 millones de jugadores, sin contar los millones de preguntas contestadas, los millones de impactos, los millones de reproducciones de los vídeos y los cientos de miles de fans nuevos en Facebook y Twitter.

Pero sobre todo, 4 personas con nombre y apellidos que podrán contar a sus nietos una historia: cómo vencieron a todos los grandes expertos en fútbol de Latinoamérica. Y toda esta experiencia gracias al Banco Santander.

Es hora de visualizar el infinito potencial estratégico y creativo cuando "El usuario es la medida de todas las campañas".

\section{Webgrafía}

"Más de 1,4 millones de personas participan en Santander Fútbol Pasión, el concurso que busca a la persona que más sabe de fútbol en Latinoamérica”, La $5^{a}$ Pata, 26 de julio de 2016. Disponible en http://la5pata.com/2016/07/26/masde-14-millones-de-personas-participan-en-santander-futbol-pasion-el-concursoque-busca-a-la-persona-que-mas-sabe-de-futbol-en-latinoamerica/ (Consultado $22 / 07 / 2017)$

"Santander busca a la persona que más sabe de fútbol, 22 de abril de 2016". Disponible en http://chile.as.com/chile/2016/04/22/futbol/1461341269_578405. html (Consultado 22/06/2017)

"Santander consigue el récord Guiness de participación con su concurso Fútbol Pasión”. Reason Why, 8 de octubre de 2010. Disponible en https://www. reasonwhy.es/actualidad/anunciantes/santander-consigue-el-record-guiness-departicipacion-con-su-concurso-futbol (Consultado 22/06/2017) 